\title{
Development of Energy-resource-efficient Equipment and Technologies of Environmentally Safe Microwave Processing of Oil Sludges
}

\author{
Rail Idiatovich Saitov${ }^{1}$, Rinat Gazizyanovich Abdeev ${ }^{1}$, Minikhan Abuzarovich \\ Fatykhov², Eldar Rinatovich Abdeev¹, and Aigul Faritovna Khasanova ${ }^{2}$ \\ ${ }^{1}$ Bashkir State University,Ufa, Russia \\ ${ }^{2}$ Bashkir State Pedagogical University named after Akmulla, Ufa, Russia
}

\section{Abstract}

the results of the analysis of scientific papers and patent elaboration of the existing methods and technologies for the separation of water-oil emulsions made it possible to implement energy-efficient processes of microwave exposure to hydrocarboncontaining media. Based on the analysis of existing mathematical models of the direct

Corresponding Author: Rail Idiatovich Saitov alex@bgutmo.ru

Published: 31 December 2020

Publishing services provided by Knowledge E

(c) Rail Idiatovich Saitov et al. This article is distributed under the terms of the Commons Attribution License, which permits unrestricted use and redistribution provided that the original author and source are credited.

Selection and Peer-review under the responsibility of the TECHNOGEN-2019 Conference Committee.
S OPEN ACCESS and reverse oil-water emulsions structure and evaluation of the behavior of oil-water emulsions in the microwave field, a mathematical model of the interaction of microwave energy with oil-water emulsions 1 has been developed. The use of this model allows for the identification of the most effective parameters of the microwave exposure for phase separation with different compositions and dielectric parameters of emulsions. Computational experiments have been carried out to identify the dependence of the binding energy of water molecules and different grades of oil on the physicochemical properties of the emulsion and the technological factors of the sludge processing. An experimental installation of microwave sludge processing has been developed and manufactured, which allows determining the adequacy of the developed model.

Keywords: microwave processing, oil sludge, phase separation

In the oil industry, up to 25 million cubic meters of solid and liquid wastes are generated annually, which are accumulated in 5000 drilling sludge barns. Only $10 \%$ of sludge pits are liquidated annually in the industry. Oil-containing wastes pollute surface and underground waters, soil and vegetation cover, and atmospheric air. Currently used the most common methods for the processing of oil sludge, such as chemical, biological, thermal, physico-chemical, filtering and settling, centrifugation with inefficiency and high cost, have a number of other disadvantages, the main of which are the burning of "useful" hydrocarbons, the formation of large volumes carbon dioxide and other toxic gases, low productivity, the inability to use at low temperatures, inapplicability to hard to stratify high wild oil sludge. In addition, they cannot be used in the conditions of oil refineries, which are one of the sources of oil sludge, the processing of which and the 
technological stream of oil refining, i.e. «In place», could significantly reduce the amount of waste generated [1].

We are developing a technology for the processing of oil sludge based on new highly efficient methods and equipment that will ensure safety for the environment and human health, as well as eliminate the above-mentioned disadvantages of existing technologies. Currently, one of the promising technologies in the oil and refining industries is considered to be microwave processing of hydrocarbon compounds to reduce viscosity during transportation, separation of stable emulsions during primary oil refining, utilization of drilling oil sludge waste and petrochemical production waste $[2,3]$. The parameters of microwave processing in the last stage have to be studied experimentally, but the frequency, power of the generator, and exposure time must be determined by at least rough calculations, because, firstly, there are several hundred varieties of oil and oil sludge, and secondly, microwave generators are produced only for several fixed frequencies, the most accessible of which is $2.4 \mathrm{GHz}$, which, by the way, explains their sweeping application in experiments. In this case, the separation of the phases of the emulsion occurs mainly due to heating. The main goal of our work is to develop energy-efficient low-temperature technologies for environmentally safe microwave processing of oil sludge waste. For this, it is necessary to determine the optimal modes of microwave exposure. Under certain assumptions, using energy relations, this problem can be solved to a first approximation. To do this, we proposed the simplest model for determining the minimum microwave field strength, on which the power of the generator depends. The resonance frequency of water molecules is known [4]. However, taking into account the small penetration depth of the microwave wave, it is also necessary to study frequencies close to the resonance at which the separation effect does not significantly decrease. To do this, we use the expression

$$
\mu_{\Sigma}=\alpha_{e} E
$$

where $\mu_{\Sigma}$ - total dipole moment of water molecules and hydrogen-carbon, oxygencarbon bonds present in water-oil and oil-water emulsions, $\mathrm{CL}$ m; $\alpha$ - electron polarizability of atoms, $\mathrm{m} 3 ; E$ - electric field strength, $\mathrm{V} / \mathrm{m}$.

Where from $E=\mu_{\Sigma} / \alpha$. Since the parameters $\mu_{\Sigma}$ and $\alpha$, different for different molecules and bonds, select the maximum value $\mu_{\Sigma \max }=11,1210^{-30}$ and minimum $\alpha_{\min }=0,4810^{-30}$ from the emulsions present in water-oil and oil-water emulsions, which will determine the minimum electric field strength necessary for breaking the emulsion equal to 100 $\mathrm{B} / \mathrm{M}$, under the worst conditions. This is the top score $E$. Now we estimate the heating 
temperature under normal conditions at the obtained value $E$, using our model of heating multicomponent mixtures [5]

$$
T(r)=T_{0}+S_{0} \sum_{i=1}^{n} k_{i} \mathrm{~F}_{e i} \frac{\mathrm{e}^{-2 \alpha_{i} r}\left(\exp \left(4 \alpha_{i}^{2} a_{i}^{2} \mathrm{t}\right)-1\right)}{2 \lambda_{a m i} \alpha_{i}}
$$

The calculation results are shown in the graph (Figure 1).

The dependence of the temperature of the emulsion on the heating time, time seconds

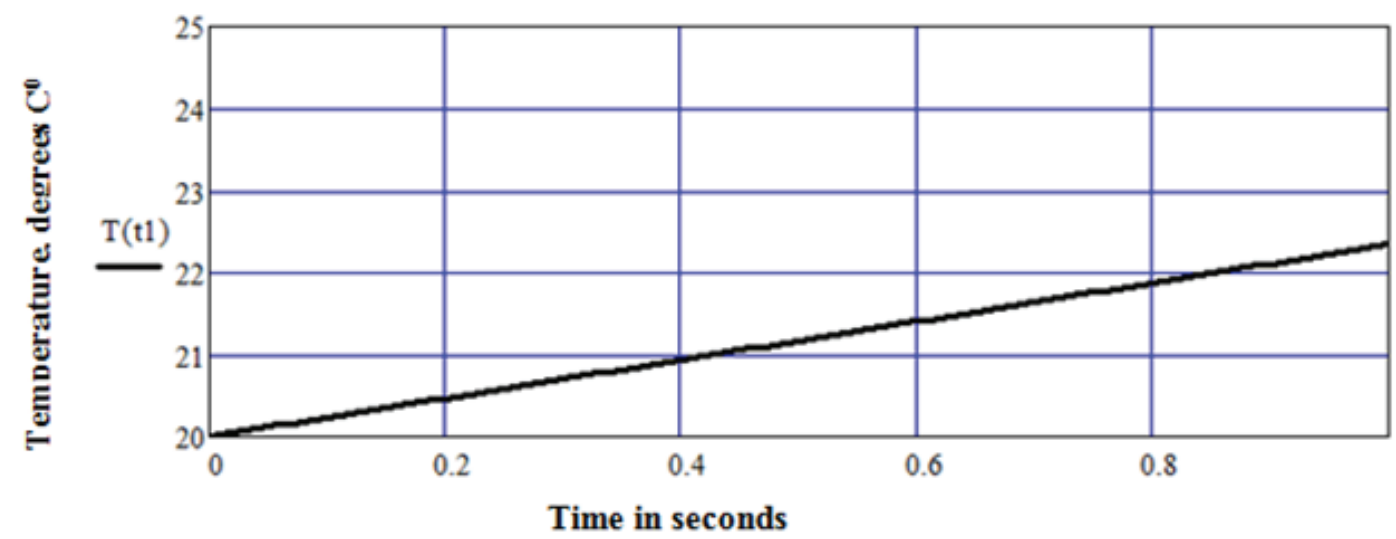

Figure 1: The temperature dependence of the heating surface of the emulsion for 1 second

A computational experiment was carried out for a frequency of a microwave generator of $10 \mathrm{GHz}$, an initial emulsion temperature of $20^{\circ} \mathrm{C}$, a water content in the emulsion of $40 \%, E=100 \mathrm{~V} / \mathrm{m}$. It can be seen from the graph that the temperature of the emulsion on the surface rose by $2.4^{\circ} \mathrm{C}$ in $1 \mathrm{~s}$. It should be noted that the model reflects the ideal case when processing is carried out by electromagnetic action during normal incidence of a plane electromagnetic wave on the boundary of the oil sludge with constant electrophysical parameters. It is unrealistic to provide such conditions during heating, respectively, of high generator powers. Another thing with low-temperature processing, when the effective exposure time can be nanoseconds, which virtually removes the restriction on the flow rate of oil sludge. It is not difficult to ensure that the vast majority of the emulsion enters the microwave field for at least a few nanoseconds. In this case, the temperature from the action of microwave energy practically does not increase.

Thus, the low-temperature separation of the emulsion is possible due to the breaking of chemical bonds under the influence of an electromagnetic field, rather than heating. Note that, ceteris paribus, if the field strength is increased 100 times, the surface will heat up to $600 \mathrm{OC}$ in 3 minutes, which is unacceptable for reasons of safety and the possibility of coking of oil sludge. In addition, heating in the stream also becomes 
problematic since for heating only the surface to $60 \mathrm{OC}$ it takes about $30 \mathrm{~s}$, and this is at a power of $50 \mathrm{~kW}(\mathrm{E}=10000 \mathrm{~V} / \mathrm{m})$ and under conditions close to ideal. In fact, the contradiction between the requirements of uniform heating in volume and ensuring the necessary flow rate is insurmountable. Therefore, the separation of the phases of the emulsion by microwave heating has its significant, rather even unremovable, disadvantages.

\section{Conclusion}

Thus, the low-temperature separation of the emulsion will eliminate the disadvantages of existing methods, such as the burning of "useful" hydrocarbons, the formation of large volumes of carbon dioxide and other toxic gases, low productivity, the inability to use at low temperatures, and inapplicability to hard-to-decompose high-viscosity oil sludge. In addition, this technology and equipment can be used in the process stream of oil refineries, which will significantly reduce the amount of waste generated.

This work was supported by the RFBR grant No. 18-29-24178

\section{References}

[1] Chertes, K. L., et al. (2013). Oil Sludge Processing Technology. Journal: Environmental Protection in the Oil and Gas Complex, issue 6, pp. 35-39.

[2] Kovaleva, L. A., Zinatullin, R. R. and Minnigalimov, R. Z. (2008). The Study of the Destruction of Oil-Water Emulsions by a High-Frequency Electromagnetic Field. Journal: Proceedings of the Institute of Mechanics of the Ufa Scientific Center of the Russian Academy of Sciences, vol. 6, pp. 101-106.

[3] Cao, B. (2017). Study of the Effect of Microwave Radiation on the Properties of High Viscosity Oils in order to Increase the Efficiency of their Transportation. (PhD dissertation. 2017).

[4] Debye, P. (1931). Polar Molecules. Moscow, p.247.

[5] Saitov, R. I., et al. (2018). A Mathematical Model of the Process of Electromagnetic Heating of a Multiphase Multicomponent Heavy Oil Reservoir. Bulletin of the Academy of Sciences of the Republic of Bashkortostan, vol. 29, issue 4 (92), pp. 73-79. 